\title{
Teen Stress and Substance Use Problems in Coös Survey Shows Strong Community Attachment Can Offset Risk
}

\author{
KAREN T. VAN GUNDY AND MEGHAN L. MILLS
}

$\Lambda$ lcohol and drug problems typically emerge in youth and young adulthood, and rural youth often begin to experience such problems earlier in life than their urban counterparts. ${ }^{1}$ Youth is also a time of growing social strains, such as those related to family conflict or peer bullying. Such strains can interfere with positive development and growth, and can increase risk for later substance abuse. ${ }^{2}$ Rural youth may be especially vulnerable to stress and strain due to declining local economies. ${ }^{3}$ According to recent research, youth in rural Coös County, New Hampshire, the subject of this brief, appear to experience higher levels of social stress than youth in more urban New Hampshire counties. ${ }^{4}$

Yet rural youth also possess important personal and social resources that may offset some of the negative effects of greater social stress. Compared with their urban counterparts, for instance, rural residents tend to show higher levels of community connection and attachment. ${ }^{5}$ Similarly, Coös youth appear to be very attached to their communities, ${ }^{6}$ and those youth who are most involved in local group activities-like community teams, clubs, and events-tend also to earn the highest school grades, feel the greatest sense of school belonging, and are the most optimistic about their futures. ${ }^{7}$ These youth also report the lowest levels of alcohol and drug use. ${ }^{8}$

The purpose of this brief is to explore how social stress and community attachment are related to problem alcohol and drug use for Coös girls and boys. The brief uses survey data from the Coös Youth Study (CYS), which includes self-reported information from 564 Coös youth who were in seventh and eleventh grades in 2008, and who were surveyed again one year later (in 2009) when they were in eighth and twelfth grades. At this point there were two complete years of data, so the research could use measures of social stress and community attachment from the 2008 survey and measures of alcohol and drug use behaviors from the 2009 survey in an attempt to better understand how social stress and community attachment may predict subsequent substance use problems. We were particularly interested in seeing if youth facing the most life strains would benefit from community attachment, and if these processes were similar for girls and boys in Coös County.

\section{Key Findings}

- Stressed-out youth more often report substance use problems than youth with less stress.

- Nearly one-fourth of the Coös youth surveyed (22 percent of boys and 23 percent of girls) reported at least one alcohol or drug use-related problem.

- Girls are more "stressed out" than boys, but they are also more attached to their communities.

- Coös youth who feel more connected to their communities are less likely to report substance use problems one year later.

- A strong sense of community attachment appears to protect some highly stressed Coös youth, especially boys, from problem substance use.

\section{Boys Will Be Boys?}

Historically, boys have tended to use and abuse alcohol and other drugs more than girls, but this trend appears to be changing. Among the Coös youth we surveyed, girls and boys reported using alcohol and drugs at similar levels. With regard to alcohol use, about 47 percent of girls and 51 percent of boys reported drinking in the past six months. Girls were slightly, though not statistically significantly, less likely to report using drugs other than alcohol than were boys (24 percent of girls as compared to 30 percent of boys). Most importantly, alcohol and drug use-related problems were similar for girls and boys; about 23 percent of girls and 22 percent of boys reported at least one of fifteen problems related to substance use. The ten most common problems are presented in Table 1 . 
Table 1: The Ten Most Common Substance Use Problems for Coös Girls and Boys

\begin{tabular}{|c|c|c|}
\hline In the past 6 months... & Girls & Boys \\
\hline $\begin{array}{l}\text { 1. I was under the influence of alcohol or drugs when I could've gotten hurt physically (like while } \\
\text { swimming, climbing, using a knife, crossing against the traffic, driving, etc.). }\end{array}$ & $9.8 \%$ & $10.0 \%$ \\
\hline 2. I wanted to quit or cut down on my alcohol or drug use. & 9.1 & 8.2 \\
\hline 3. I used more alcohol or drugs than I meant to use. & 8.4 & 8.6 \\
\hline 4. My alcohol or drug use caused problems with my emotions or nerves. & 7.7 & 4.6 \\
\hline 5. My alcohol or drug use caused problems with my physical health. & 5.9 & 4.3 \\
\hline 6. I accidently hurt myself while using alcohol or drugs. & 5.6 & 5.0 \\
\hline 7. I was under the influence of alcohol or drugs at school or work. & $5.2^{*}$ & 10.0 \\
\hline 8. My alcohol or drug use caused problems with my family. & 4.9 & 5.7 \\
\hline 9. My alcohol or drug use caused problems with my friends. & 4.9 & 4.6 \\
\hline $\begin{array}{l}\text { 10. I did not perform well on important tasks (like schoolwork, chores, sports, or work) because of } \\
\text { my alcohol or drug use. }\end{array}$ & 4.2 & 6.0 \\
\hline Reported at least one alcohol or drug use-related problem & $23 \%$ & $22 \%$ \\
\hline
\end{tabular}

Note: Presented are percentages of girls and boys in 2009 who reported experiencing each problem substance use symptom in the six months prior to the 2009 survey, and for whom data are available from the 2008 survey. The sample includes data from a total of 564 youth. Asterisks denote statistically significant differences between girls and boys: ${ }^{*} p<.05$

As Table 1 shows, the most common problem was using alcohol or drugs in unsafe situations. About 10 percent of girls and boys reported being "under the influence" in situations where they could have hurt themselves, such as while driving or swimming. Interestingly, boys were nearly twice as likely as girls to report being under the influence of alcohol or drugs at school or work. This difference does not appear to derive from gender differences in work status, as girls and boys were equally likely to be employed. Yet the finding does suggest that the contexts of youth substance use may be different for girls and boys. In fact, considering the life contexts of both girls and boys is important for understanding health risk behaviors in youth more generally.

\section{Girls Are More "Stressed Out" Than Boys}

One way to explore the unique life contexts of girls and boys is by gauging their exposure to social stresses and strains. In 2008, we asked youth whether a series of stressful life events had happened to them in the twelve months prior to the survey. Twenty-six percent of girls and 16 percent of boys reported they had experienced six or more events during the past year.
As Table 2 shows, girls and boys did not differ in their experiences of the two most commonly reported stressful life events: death of a close friend or family member and the end of a romantic relationship. Girls, however, reported higher levels of interpersonal strain and conflict. That is, girls were more likely than boys to have endured the end of a close friendship, verbal abuse from peers, and theft of their property. Girls also experienced other types of family strain and conflict more so than boys. That is, girls were significantly more likely to report that someone close to them experienced alcohol or drug problems serious enough to cause problems for their families, and they were more than three times as likely as boys to have reported verbal abuse by "grown-ups in your life." On the other hand, boys more often reported exposure to physical conflict.

Our finding that girls report more interpersonal and family stressors is consistent with other studies of gender and stress. ${ }^{9}$ In general, girls are socialized to place more emphasis on relationships with family and friends than are boys. ${ }^{10}$ As a consequence, girls tend to encounter more relationship strains. Yet, as we discuss below, social stress appears to increase alcohol or drug problems for both girls and boys. 
Table 2: The Ten Most Common Social Stressors for Coös Girls and Boys

\begin{tabular}{|c|c|c|}
\hline In the past 12 months... & Girls & Boys \\
\hline 1. Did a close friend or family member die? & $43.8 \%$ & $38.3 \%$ \\
\hline 2. Did you and your boyfriend/girlfriend "break up"? & 43.5 & 42.2 \\
\hline 3. Did a close friendship end? & $42.1^{* * *}$ & 17.5 \\
\hline 4. Did anyone steal something from you and never give it back? & $32.2^{*}$ & 23.2 \\
\hline $\begin{array}{l}\text { 5. Did you get scared or feel really bad because kids were calling you names, saying mean things to } \\
\text { you, or saying that they didn't want you around? }\end{array}$ & $31.5^{* * *}$ & 12.1 \\
\hline 6. Did someone close to you drink or use drugs so often that it caused problems for your family? & $27.3^{* *}$ & 17.5 \\
\hline 7. Did anyone break or ruin any of your things on purpose? & 27.3 & 20.7 \\
\hline 8. Did anyone hit or attack you on purpose? & $23.5^{*}$ & 32.2 \\
\hline 9. Did you have a very bad accident or injury? & 22.4 & 26.1 \\
\hline $\begin{array}{l}\text { 10. Did you get scared or feel really bad because grown-ups in your life called you names, said mean } \\
\text { things to you, or said they didn't want you? }\end{array}$ & $20.3^{* * *}$ & 6.4 \\
\hline Reported six or more stressful life events & $26 \% * *$ & $16 \%$ \\
\hline
\end{tabular}

Note: Presented are percentages of girls and boys who reported experiencing each event in the twelve months prior to the 2008 survey, and for whom data are available from the 2009 survey. The sample includes data from a total of 564 youth. Asterisks denote statistically significant differences between girls and boys: ${ }^{*} p<.05 ;{ }^{* *} p<.01 ;{ }^{* * *} p<.001$.

\section{Social Stress Elevates Risk For Problem Substance Use}

Our analyses showed that exposure to social stress in 2008 elevated youth risk for alcohol or drug use problems one year later (in 2009). For youth who reported fewer than six stressful life events in the 2008 survey, about 21 percent of girls and 19 percent of boys reported at least one substance use problem in the 2009 survey (see Figure 1). Youth who experienced six or more stressful events, however, were at a statistically significantly greater risk: 29 percent of girls and 32 percent of boys with high stress levels in 2008 reported at least one substance use problem in 2009.

From our findings it seems clear that social stress is associated with problem alcohol or drug use among Coös youth. High levels of social stress are related to greater substance use problems for both girls and boys. Even though girls encounter more social stressors than boys, their substance use problems do not exceed those of boys. This may be due to their tendency to draw on support from friends and family to cope with stress. For both girls and boys, the community may be an important source of support, and a sense of attachment to that community may lessen risk for problem alcohol or drug use.
Figure 1: Stress InCreases Risk for Problem SUBSTANCE USE

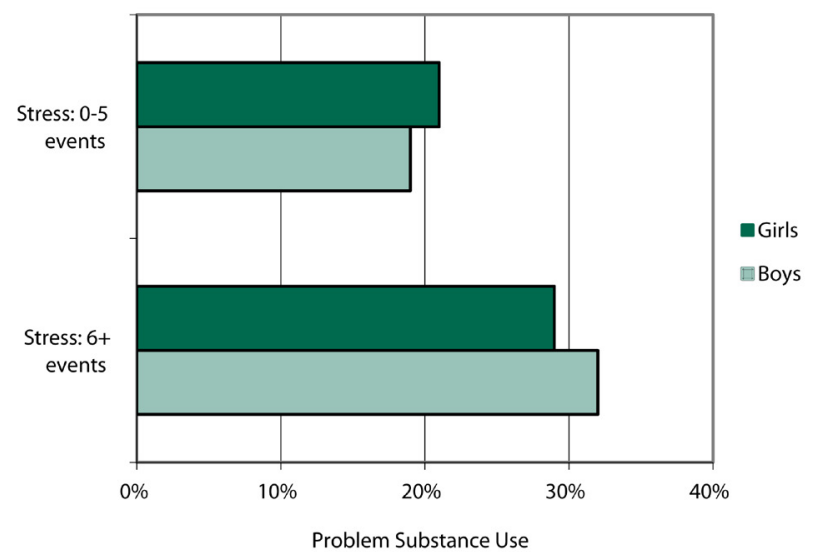

Note: Presented are the percentages of girls and boys who reported at least one problem substance use symptom in the 2009 survey by their reported stress exposure in the 2008 survey. The sample includes data from a total of 564 girls and boys. 


\section{Community Attachment Reduces Risk For Problem Substance Use}

Community attachment is commonly defined as an emotional connection and sense of belonging with regard to the area in which one resides. ${ }^{11}$ Research consistently reveals that community attachment is associated with numerous positive outcomes for youth. ${ }^{12}$ In the 2008 survey, we measured community attachment by asking the Coös youth whether they agreed or disagreed with the statement: "I care about my community." The vast majority of girls and boys agreed with this statement, which suggests a high degree of community attachment among Coös youth. Girls were significantly more likely to agree than were boys ( 82 percent versus 68 percent of boys). In addition, we found that our community attachment measure predicted problems with subsequent alcohol or drugs one year later (see Figure 2).

Figure 2: Community Attachment Reduces Risk for Problem Substance Use

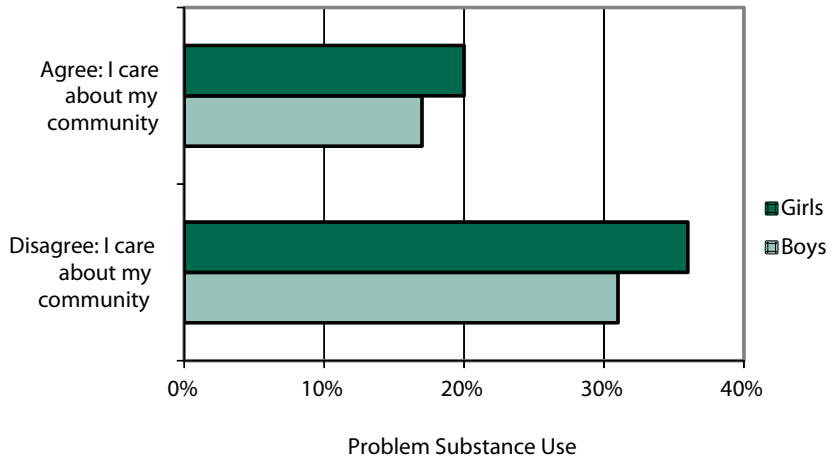

Note: Presented are the percentages of girls and boys who reported at least one problem substance use symptom in the 2009 survey by their reported community attachment in the 2008 survey. The sample includes data from a total of 564 youth.

As Figure 2 illustrates, those with greater community attachment had lower levels of problem substance use. Girls and boys who agreed that they "care about my community" reported alcohol or drug use problems less often than those who did not report caring about their community. About 20 percent of girls and 17 percent of boys with high community attachment in 2008 reported substance use problems one year later (in 2009). In contrast, 36 percent of girls and 31 percent of boys with lower community attachment reported at least one substance use problem a year later. Therefore, it seems that building a sense of community attachment among both girls and boys may reduce risky substance use behaviors in rural areas like Coös County.

\section{"Stressed Out" Youth Benefit From Community Attachment}

We also wondered whether high levels of community attachment might protect highly stressed youth from engaging in problem alcohol or drug use behaviors. We were interested in exploring whether "stressed out" girls and boys were equally protected by community attachment. We found that, among youth who reported six or more stressful life events in the 2008 survey, community attachment reduced problem use of alcohol or drugs in 2009. This effect was particularly pronounced for boys. Figure 3 shows these results for highly stressed girls and boys in Coös County.

\section{Figure 3: For "Stressed OUt" Girls and Boys, Community Attachment Reduces Risk for Problem Substance Use}

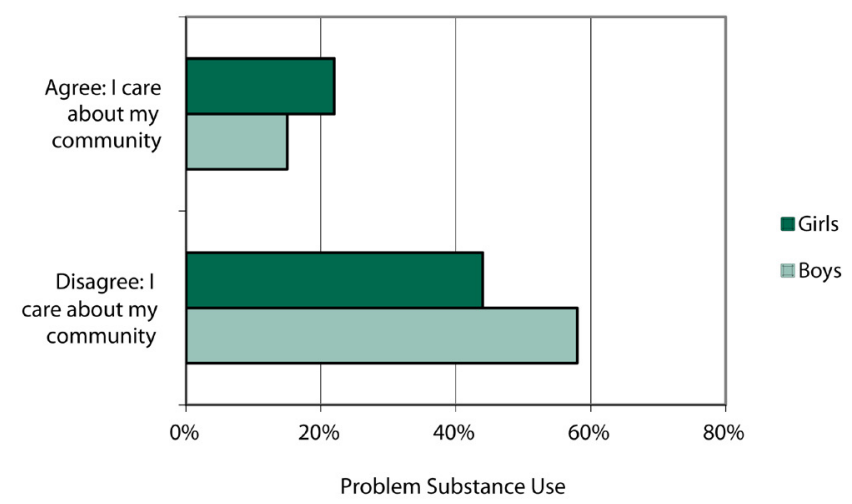

Note: Presented are the percentages of highly stressed girls and boys who reported at least one problem substance use symptom in the 2009 survey by their reported community attachment in the 2008 survey. Included here are data only from the 121 most "stressed out" youth in the sample.

Among highly stressed girls who agreed that they care about their community, 22 percent reported at least one substance use problem one year later. In contrast, highly stressed girls who did not report a strong sense of community were twice as likely to report problem substance use one year later (44 percent). For boys, the stress-buffering effect of community attachment was even more pronounced. About 15 percent of highly stressed boys with strong community attachment reported problem substance use one year later. This compares with nearly 58 percent of highly stressed boys with low community attachment. Therefore, community attachment not only reduces risk for problem alcohol or drug use for Coös youth generally, but it may be especially helpful for youth, particularly boys, who are exposed to high levels of stress and strain. 


\section{Conclusion}

Overall, we find that Coös girls and boys tend to experience similar levels of problem substance use. Although girls report higher levels of social stress than boys do, both girls and boys who are exposed to high levels of stress show an increased risk for subsequent problem alcohol and drug use. Policies and practices that emphasize coping and stress management are therefore likely to be effective for combating problem substance use in rural areas like Coös County. For instance, family-focused and school-based drug prevention and intervention programs, like Preparing for the Drug Free Years (PDFY) and Life Skills Training (LST), hold great promise for aiding rural youth, especially girls, in the development of healthy drug-related coping skills, attitudes, and knowledge. ${ }^{13}$

Consistent with prior research, we find that strong attachments to community reduce risk for problem substance use in Coös boys and girls. ${ }^{14}$ We recommend, then, that drug policies and practices in rural areas strive to promote a sense of community. Studies have shown that community attachment can be fostered in youth programs that: provide youth with leadership and responsibility; give youth opportunities to participate in decision-making; and allow youth to contribute to an organization that shares their beliefs and values. Youth involvement in community-based organizations or extra-curricular activities that meet the above criteria also allow for the growth of community cohesion, as does the sense among youths that their opinions matter. In fact, the most successful community-building programs involve not only professionals and parents, but the entire communityincluding its youth members. ${ }^{15}$

Our analyses also reveal that even the most "stressed out" youth benefit from the protective effects of caring about one's community. That is, not only does perceived attachment to one's community diminish risk for substance use problems generally, it can actually serve to buffer the harmful effects of youths' exposure to stressful life circumstances. This is noteworthy because it means that even the most disadvantaged or "at risk" youth can share in the favorable effects of community-focused drug programs like those described above.

Interestingly, a sense of community attachment may be particularly important for boys facing high levels of stress and strain. While it is noteworthy that "stressed out" girls who do not care about their communities are twice as likely as "stressed out" girls who care about their communities to experience substance use problems, boys seem to be even more protected by a sense of community attachment. That is, "stressed out" boys who report not caring about their communities are nearly four times as likely to report substance use problems as "stressed out" boys who care about their communities. In light of these findings, and the findings in prior research that family-focused and school-based drug programs benefit girls more than boys, ${ }^{16}$ we recommend that future drug prevention strategies pay special attention to fostering a stronger sense of community attachment among "disconnected" boys in rural America.

In sum, girls and boys in rural areas like Coös County may encounter high levels of social stress, yet often they also possess vital personal and social resources-like community attachment - that can mitigate the damaging effects of stress and strain. While we may be unable to control the number or severity of stressors that girls and boys experience, we can work to build on the strengths of our communities to safeguard youth from the harmful effects of those stressors and strains. Toward that effort, the Coös Youth Study team is committed to further data collection that will allow us to better understand how social stress, community attachment, and substance use patterns develop and change as youth transition to adulthood. This important work relies on the generous participation of the study respondents, their families, teachers, school officials, and the broader communities involved in this study. So far, our results suggest that fostering and maintaining community connectedness may be crucial for easing youth stress and reducing problem substance use in Coös County. The most successful drug programs are likely to be those aimed at building community cohesion, drawing on the existing strengths of communities, and tailoring programs "to the specific cultural milieu" of the rural communities they serve. ${ }^{17}$

\section{E N D N O T E S}

1. Karen Van Gundy, "Substance Abuse in Rural and Small Town America," Reports on Rural America, Volume 1, Issue 2 (Durham, NH: Carsey Institute, University of New Hampshire, 2006).

2. Karen Van Gundy and Cesar J. Rebellon, "A Life-course Perspective on the 'Gateway Hypothesis," Journal of Health and Social Behavior 51 (2010): 244-259.

3. Chris R. Colocousis, "The State of Coös County: Local Perspectives on Community and Change," Issue No. 7 (Durham, NH: Carsey Institute, University of New Hampshire, 2008).

4. Karen Van Gundy et al., "Perceived Community Cohesion and the Stress Process in Youth," Rural Sociology 76(3) (2011): 293-318.

5. Van Gundy, "Substance Abuse in Rural and Small Town America."

6. Cesar J. Rebellon, Nena F. Stracuzzi, and Melissa Burbank, "Youth Opinions Matter: Retaining Human Capital in Coös County," Issue No. 19 (Durham, NH: Carsey Institute, University of New Hampshire, 2010). 
7. Erin Hiley Sharp, “Out-of-School Time Matters: Activity Involvement and Positive Development among Coös County Youth," Issue No. 17 (Durham, NH: Carsey Institute, University of New Hampshire, 2010a).

8. Erin Hiley Sharp, “Too Much Free Time: Coös County Youth Who Are Least Involved in Out-of-School Activities Are Most Likely to Use Drugs and Alcohol," Issue No. 18 (Durham, NH: Carsey Institute, University of New Hampshire, 2010b).

9. Karen Van Gundy, "Gender, the Assertion of Autonomy, and the Stress Process in Young Adulthood," Social Psychology Quarterly 65 (2002): 346-63.

10. Karen Van Gundy et al., "Gender Role Orientations and Alcohol Use among Moscow and Toronto Adults," Social Science and Medicine 61 (2005): 2317-30.

11. Gene L. Theodori, "Levels of Analysis and Conceptual Clarification in Community Attachment and Satisfaction Research: Connections to Community Development," Journal of the Community Development Society 31(1) (2000): 35-58; Gene L. Theodori and A.E. Luloff, "Urbanization and Community Attachment in Rural Areas," Society \& Natural Resources 13 (2000): 399-420.

12. Theodori, "Levels of Analysis and Conceptual Clarification in Community Attachment and Satisfaction Research: Connections to Community Development."

13. W. Alex Mason et al., "Gender Moderation and Social Developmental Mediation of the Effect of a Family-Focused Substance Use Preventive Intervention on Young Adult Alcohol Abuse," Addictive Behaviors 34 (2009): 599-605; W. Alex Mason et al., "Influence of a Family-Focused Substance Use Preventive Intervention on Growth in Adolescent Depressive Symptoms," Journal of Research on Adolescence 17(3) (2007): 541-64; Judith R. Vicary et al., "Results of a 3-Year Study of Two Methods of Delivery of Life Skills Training," Health Education and Behavior 33(3) (2006): 325-339.

14. Laura V. Scaramella and Angela W. Keyes, “The Social Contextual Approach and Rural Adolescent Substance Use: Implications for Prevention in Rural Settings," Clinical Child and Family Psychology Review 4(3) (2001): 231-51.

15. M.A. Brennan, Rosemary V. Barnett, and Eboni Baugh, "Youth Involvement in Community Development: Implications and Possibilities for Extension," Journal of Extension 45(4) (2007).

16. Mason et al., "Gender Moderation and Social Developmental Mediation of the Effect of a Family-Focused Substance Use Preventive Intervention on Young Adult Alcohol Abuse."; Mason et al., "Influence of a Family-Focused Substance Use Preventive Intervention on Growth in Adolescent Depressive Symptoms."; Vicary et al., "Results of a 3-Year Study of Two Methods of Delivery of Life Skills Training."
17. Scaramella and Keyes, "The Social Contextual Approach and Rural Adolescent Substance Use: Implications for Prevention in Rural Settings."

\section{A C K N O W L E D G E M E N T S}

The Coös Youth Study team thanks the students who are participating in this research project and the superintendents, principals, guidance counselors, and administrators who helped the team collect the data.

\section{ABOUT THE AUTHORS}

Karen T. Van Gundy is a faculty fellow at the Carsey Institute and an associate professor of sociology at the University of New Hampshire. Her work applies stress and life-course perspectives to understanding physical, emotional, and behavioral well-being.

Meghan L. Mills is a doctoral student of sociology at the University of New Hampshire and a research assistant at the Carsey Institute. Her dissertation (in progress) examines the impact of stress and aspirations on well-being for rural youth and emerging adults. 


\section{THE CARSEY INSTITUTE COÖS YOUTH STUDY}

The Carsey Institute is conducting a panel study of Coös County youth that will provide data about the attitudes and experiences of the county's youth as they approach young adulthood and face the decision to remain in their community, seek opportunities elsewhere, or leave for an education and then return. By following the entire populations of two age groups over a ten-year period, we will help North Country leaders gain a better understanding of young people's decision making.

\section{RESEARCH TEAM}

CESAR J. REBELLLN is a faculty fellow at the Carsey Institute and an associate professor in sociology at the University of New Hampshire. His primary research interests focus on family and peer correlates of juvenile crime and delinquency, with a particular emphasis on the manner in which delinquency may yield reinforcing social rewards among adolescents.

ERIN Hiley Sharp is a Carsey Institute faculty fellow and assistant professor in family studies at the University of New Hampshire. Her research interests include activity involvement as a context for adolescent development; parental, family, and broader contextual influences on adolescent development; and prevention research and theory from a positive youth development perspective.

NenA F. StRAcuzzi is a senior teaching and research fellow in the doctorate of education program at Northeastern University and a faculty fellow at the Carsey Institute. Her research for the Carsey Institute has focused primarily on vulnerable youth and families.

Corinna Jenkins Tucker is a faculty fellow at the Carsey Institute and an associate professor in family studies at the University of New Hampshire. Her primary research interests focus on the nature and context of family relationships and their links to adolescent psychosocial development.

KAREN T. VAN GUNDY is a faculty fellow at the Carsey Institute and an associate professor in sociology at the University of New Hampshire. Her work investigates the mechanisms by which life circumstances and social statuses influence variations in health, emotional, and behavioral outcomes. 


\section{$\triangle$ UNIVERSITY - of NEW HAMPSHIRE}

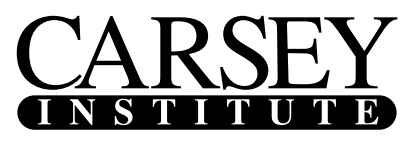

Building knowledge for families and communities

The Carsey Institute conducts policy research on vulnerable children, youth, and families and on sustainable community development. We give policy makers and practitioners timely, independent resources to effect change in their communities.

This work was supported by the The Neil and Louise Tillotson Fund of the New Hampshire Charitable Foundation.

Huddleston Hall

73 Main Street

Durham, NH 03824

$(603) 862-2821$

www.carseyinstitute.unh.edu 